\title{
Simulação na educação médica: processo de construção de pacientes padronizados para comunicação de más notícias
}

\author{
Simulation in medical education: the process of standardized patient development for breaking bad news
}

\author{
Fernanda Cristine Quint ${ }^{1}$ (D) |fernandacquint@gmail.com \\ Ana Leticia Pereira' (1) analeticiap42@gmail.com \\ Ana Paula Rosa Isquierdo' (1) ana.isquierdo10@gmail.com \\ Giovana Ferreira de Freitas Miranda' (1) giovanaffmiranda@gmail.com \\ Ursula Bueno do Prado Guirro' (D) ursulaguirro@gmail.com
}

\begin{abstract}
RESUMO
Introdução: Comunicação de más notícias refere-se às informações médicas que rompem de maneira adversa e negativa as expectativas de um paciente. Trata-se de um momento delicado da relação médico-paciente. O role playing com pacientes padronizados (PP) é uma alternativa para o ensino da comunicação, porém é desafiador construir roteiros e cenários semelhantes com a realidade, especialmente quando não se dispõe de atores profissionais.
\end{abstract}

Objetivo: Este estudo teve como objetivo descrever a construção de PP a partir da experiência dos estudantes para o treinamento da comunicação com outros discentes de Medicina.

Método: Estudantes de Medicina participaram voluntariamente da formação teatral e se dedicaram à construção de $\mathrm{PP}$, com supervisão de docentes médicos e de atrizes, para oficinas de comunicação de más notícias. Para a construção dos PP, criaram-se diagnósticos médicos desfavoráveis, e estabeleceram-se os seguintes tópicos: perfil emocional, historicidade, instruções, progressões e possíveis desfechos, objetivos primário e secundário, e elementos facilitadores das cenas. Ensaiou-se exaustivamente para que os PP apresentassem a mesma reação em diferentes atitudes nas simulações. A participação nas oficinas foi aberta aos estudantes de Medicina interessados. Aferiu-se a qualidade das cenas pela sensação de realidade proporcionada aos participantes das oficinas.

Resultado: Dez estudantes com idades entre 19 e 26 anos, de diferentes semestres, participaram do treinamento, do desenvolvimento de PP e das oficinas de simulação. Desenvolveram-se quatro cenas: Mariana recebeu diagnóstico de HIV e revelou violência sexual (60 cenas), Caroline e Marcelo receberam diagnóstico de câncer e necessidade de cirurgia (53 cenas), Thaís recebeu diagnóstico de insensibilidade androgênica e presença de gônadas masculinas (31 cenas), e Roger ou Rosana recebeu diagnóstico de retinose pigmentar e cegueira progressiva (22 cenas). Todos os PP proporcionaram sensação de realidade aos diferentes participantes das oficinas.

Conclusão: Foi possível construir PP com estudantes de Medicina, apoiados por docentes, com a finalidade de participação em oficinas de comunicação de más notícias para outros discentes de Medicina que apontaram, em sua maioria, sensação de realidade com as cenas. Os estudantes atores se engajaram no processo e desenvolveram habilidades de comunicação e de empatia, características necessárias para a prática médica.

Palavras-chave: Simulação de Paciente; Role Playing; Comunicação de Más Notícias; Educação Médica.

\begin{abstract}
Introduction: Breaking bad news is giving medical information that adversely and negatively disrupts a patient's expectations. This is a delicate moment in the doctor-patient relationship. Role playing with standardized patients (SP) is one method for teaching such communication skills, but it is challenging to construct scripts and scenarios that reflect reality, especially when professional actors are not used.

Objective: To describe the construction of SP based on the students' experience for communication skills training with other medical students.

Method: Medical students voluntarily participated in theatrical training, and worked on developing SPs, under the supervision of medical professors and actors, for breaking bad news workshops. For the construction of the SPs, unfavorable medical diagnoses were created, establishing an emotional profile, history, instructions, progressions and possible outcomes, primary and secondary objectives, and facilitating elements of the scenes. It was exhaustively tested so that the SP presented the same reaction in different attitudes in the simulations. Participation in the workshops was open to interested medical students. The quality of the scenes was measured by the sense of reality given to the workshop participants.

Result: Ten students aged between 19 and 26 years, from different semesters, participated in the training, the SP development and role-play workshops. Four scenes were developed: Mariana was diagnosed with HIV and revealed sexual violence (60 scenes), Caroline and Marcelo who were diagnosed with cancer and needed surgery (53 scenes), Thais received a diagnosis of androgen insensitivity and presence of male gonads (31 scenes) and Roger or Rosana with retinitis pigmentosa and progressive blindness (22 scenes). All the SPs gave a sense of reality to the different workshop participants.

Conclusion: It was possible to develop SPs with medical students, supported by professors, with the purpose of participating in workshops to communicate bad news to other medical students who perceived, for the most part, a sense of reality in the scenes. The student actors engaged in the process and developed communication and empathy competencies; characteristics necessary for medical practice.
\end{abstract}

Keywords: Patient Simulation; Role-Playing; Breaking Bad News; Medical Education.

${ }^{1}$ Universidade Federal do Paraná, Curitiba, Paraná, Brasil.

Editora-chefe: Rosiane Viana Zuza Diniz. | Editora associada: Daniela Chiesa.

Recebido em 13/03/21; Aceito em 26/09/21. | Avaliado pelo processo de double blind review. 


\section{INTRODUÇÃO}

Em relação a uma informação sobre a saúde, as más notícias ou notícias difíceis foram definidas como um diagnóstico desfavorável que o médico comunica ao paciente. Tal informação romperá de maneira adversa e negativa as expectativas do paciente sobre o futuro ${ }^{1-3}$. É importante que o médico seja capaz de comunicar da maneira adequada, cuidadosa e empática, pois trata-se de um momento crítico da relação entre ele e o paciente que dará início a uma sequência de enfrentamentos e situações que este enfrentará. O protocolo SPIKES, trata-se de um anacrônimo (setting up, perception, invitation, knowlodge, emotion, summarize) foi desenvolvido justamente com o propósito de orientar profissionais de saúde na comunicação de más notícias ${ }^{4}$.

Os médicos e estudantes de Medicina relataram, em sua maioria, que se sentiam inseguros e despreparados e que não receberam treinamento para a comunicação de más notícias durante a formação ${ }^{5-7}$. A falta de preparo, muitas vezes, reflete a inabilidade de lidar com os próprios sentimentos aflorados durante a comunicação de notícias difíceis ${ }^{7}$. O profissional pode se sentir inseguro e optar pelo distanciamento emocional, proporcionando um discurso excessivamente técnico e pouco acolhedor, que resultará na falta de acolhimento das emoções e no maior sofrimento do paciente ${ }^{3,5-7}$. Com isso, dada a vulnerabilidade do momento tanto para o médico como para o paciente $e^{5-8}$, percebe-se a necessidade propiciar momentos de aprendizagem e de aperfeiçoamento da comunicação de notícias difíceis durante a graduação em Medicina.

O role playing é uma metodologia ativa de ensino que tem se mostrado eficaz para a aquisição e o treinamento de habilidades de comunicação de más notícias entre estudantes e médicos ${ }^{5-7,9-11}$. A técnica é baseada nas artes teatrais e na improvisação, e consiste em simulações de consultas e outros atos médicos, em que estudantes interagem com pacientes simulados previamente desenvolvidos para esse cenário ${ }^{9-13}$.

O objetivo desta pesquisa foi descrever o processo de construção de pacientes padronizados (PP), com a participação de estudantes de Medicina, em cenários simulados do tipo role playing, com a temática da comunicação de más notícias. A proposta era que os estudantes de Medicina que participassem ativamente do processo de construção de PP, com supervisão de docentes, pudessem vivenciar o processo criativo e adquirir habilidades de comunicação de más notícias.

\section{MÉTODOS}

O estudo respeitou as normas de ética em pesquisa vigentes e foi aprovado pelo Comitê de Ética em Pesquisa da instituição e registrado sob o Certificado de Apresentação para Apreciação Ética (CAAE) n 91407818.0.0000.0102.
De maneira geral, a pesquisa se dividiu em dois momentos: processo de desenvolvimento de PP, com ensaios e aprimoramentos das cenas, e realização de oficinas de simulação de cenários de comunicação de más notícias com os PP.

\section{Processo de desenvolvimento de PP}

Foram convidados para participar das atividades estudantes maiores de idade e matriculados em todos os semestres do curso de Medicina de uma universidade pública que tivessem interesse ou alguma experiência prévia em teatro amador, com o limite de 12 vagas disponíveis. Excluíramse apenas os menores de 18 anos. Dez estudantes aceitaram participar e concluíram as atividades.

Inicialmente, ministrou-se um curso de teatro, com carga horária de 30 horas, que consistiu em ensino e treinamento prático de práticas de improviso, linguagem corporal, montagem de cenas e criação e interpretação de personagens. Duas atrizes foram responsáveis pela formação teatral, e o contexto médico foi planejado por uma médica docente.

Os estudantes que participaram das atividades teatrais foram denominados estudantes atores e construíram quatro cenas com os PP, com base em perfis emocionais e situações clínicas previamente estabelecidos pelo próprio grupo. As cenas deveriam ter o contexto de uma consulta médica habitual. As características clínicas foram respeitadas ao máximo, embora tenha ocorrido alguma liberdade artística para que a má notícia pudesse ser comunicada em uma única consulta.

O conhecimento exato das doenças não deveria ser o aspecto mais relevante na construção dos PP. Evitaram-se equívocos e excesso de distratores, entretanto foram incluídas as características consideradas essenciais para a construção de um PP mais próximo da realidade. O objetivo foi propiciar a construção de PP e de um cenário médico simulado verossímil para a comunicação de más notícias.

$\mathrm{Na}$ construção dos PP, consideraram-se os elementos mínimos:

- $\quad$ Perfil emocional: os PP poderiam combinar os perfis introvertido ou extrovertido e gentil ou agressivo.

- Historicidade da pessoa: refere-se ao conjunto dos fatores que fazem parte da história de uma pessoa e que condicionam o comportamento dela a uma dada situação. Ou seja, trata-se de um resumo da vida do personagem que justifica seu comportamento e suas principais angústias no momento da consulta e em relação à notícia que será comunicada. Também direciona o nível cultural e educacional do PP, e a necessidade de adaptação de discurso do médico para entendimento do paciente. 
- Instrução aos participantes: informação que seria disponibilizada para os estudantes participantes dos cenários de simulação como médicos. $A$ informação estava fixada na porta do consultório simulado e pôde ser complementada dentro do consultório, como exames em envelopes ou na tela do computador.

- Progressão da cena e possíveis desfechos: os diferentes PP deveriam reagir de maneira semelhante, fidedigna e reprodutível aos diferentes gatilhos ofertados pelos participantes das oficinas. Além disso, foram combinados elementos verbais e não verbais de cada PP que auxiliassem os estudantes a atingir os objetivos da cena.

- Objetivo primário da cena: transcrito pela comunicação da má notícia propriamente dita, de forma completa e sem margem para dúvidas no entendimento pelo PP.

- Objetivo secundário da cena: transcrito por um desafio extra na cena, relacionado com as questões emocionais/pessoais de cada PP, claramente explicitado durante a cena.

- Elemento facilitador: estabeleceram-se para cada PP limites para que o desconforto gerado no estudante participante das oficinas não fosse exacerbado e prejudicasse o aprendizado.

As cenas foram desenvolvidas para que tivessem curta duração e viabilizassem a realização de futuras oficinas. Para esse fim, sugeriram-se inicialmente cinco minutos para cada cena, permitindo adaptação do tempo de acordo com os ensaios do grupo e testes preliminares antes das oficinas. As cenas foram exaustivamente ensaiadas e ajustadas pelo próprio grupo com técnicas de espelho e incorporação de sugestões das professoras. Os testes preliminares ocorreram na fase de ensaios, com estudantes de Medicina externos ao grupo, proporcionando correções até alcançar o que se entendeu como adequado pela equipe.

\section{Oficinas de simulação de comunicação de más notícias}

Posteriormente, as cenas desenvolvidas foram empregadas em oficinas de comunicação de más notícias, que ocorreram em dias pré-agendados, e contaram com a participação de estudantes de Medicina em geral, denominados estudantes participantes. Incluíram-se os maiores de idade, matriculados em qualquer período do curso (do primeiro ao último ano), que não participavam do grupo de teatro, com o limite de 30 estudantes por oficina.

Organizaram-se as oficinas com instruções prévias, simulação com PP e feedback coletivo após a experiência. Os participantes receberam as seguintes orientações: deveriam se concentrar na comunicação com o PP, comunicar o diagnóstico que estaria dentro do consultório e desconsiderar os detalhes da prática médica que não conhecessem.

Em cada sala de simulação, havia um estudante observador, que era um dos estudantes atores que não estava atuando naquele momento. O observador se posicionava atrás do participante e não interferia no desenvolvimento da cena, e sua função era avaliar a qualidade da comunicação. No entanto, como a avaliação da qualidade da comunicação dos estudantes participantes não faz parte deste artigo, não será descrita aqui. O resultado pode ser conhecido em outros artigos ${ }^{14,15}$.

Antes de entrar na sala de simulação, o estudante poderia ler as informações sobre o cenário. Depois disso, soava uma campainha, e ela ou ele poderia entrar e iniciar a cena até soar a segunda campainha. Poderia ainda sair quando quisesse. O participante não tinha outras informações sobre a cena. No cenário, havia um ou mais PP e um envelope com o diagnóstico. Bastava entrar, iniciar a consulta simulada e comunicar a má notícia da maneira que julgasse mais adequada.

Após as simulações, os estudantes participantes foram reunidos em roda para trocar experiências, receber orientações do protocolo SPIKES e responder a um questionário sobre a sensação de realidade proporcionada pela cena: muita sensação de realidade, alguma sensação de realidade, neutro, pouca sensação de realidade e nenhuma sensação de realidade. Desse modo, a sensação de realidade foi avaliada apenas com a finalidade de validação dos PP desenvolvidos e simulados pelos estudantes atores, e os demais resultados podem ser verificados em outros artigos ${ }^{14,15}$.

Oresultado da construção dos PP está descrito na próxima seção com base nos elementos especificados anteriormente e na sensação de realidade proporcionada aos estudantes participantes das oficinas. Além disso, contabilizaram-se o tempo dedicado à construção de cada PP e o número de discentes que participaram das simulações.

\section{RESULTADOS}

O treinamento da equipe de estudantes atores ocorreu ao longo de um semestre acadêmico, e, para as 12 vagas ofertadas, dez discentes de Medicina se voluntariaram, com idade entre 19 e 26 anos e de ambos os sexos. As oficinas de comunicação de más notícias se estenderam no semestre acadêmico subsequente. Os resultados obtidos do processo de construção dos PP, incluindo horas necessárias para a construção e ensaios, quantidade de encenações realizadas em oficinas e sensação de realidade proporcionada aos participantes, estão descritos no subtítulo de cada personagem. 


\section{Mariana}

Perfil

É introvertida e tende à agressividade, com ironias e retraimento.

- Postura na cena: os braços e as pernas permanecem cruzados no início da cena, indicando que não está aberta para o diálogo. Ela demonstra desconforto e desejo de finalizar logo a consulta. Esfrega os braços e as pernas constantemente.

\section{Historicidade}

Mulher, 24 anos, universitária. Tem um namorado de longa data. Foi vítima de violência sexual há meses e não contou a ninguém. Há 20 dias, esteve em uma unidade de atenção primária à saúde e solicitou o teste para HIV. Não foi questionada e não revelou o motivo. Na cena, ela retorna para saber o resultado do exame.

- Necessidade de adaptação de discurso: o conhecimento da PP sobre HIV foi baseado no que é veiculado pelos meios de comunicação. Não compreenderá conceitos de biologia celular, infectologia, imunologia e mecanismo de antirretrovirais. Reagirá com ironias aos eufemismos.

\section{Instrução ofertada aos participantes das oficinas}

"Mariana, 24 anos. Ela compareceu há 20 dias a uma unidade de atenção primária à saúde, consultou-se com outro médico e pediu exames de rotina, incluindo teste de HIV. Não há outras informações sobre a história médica da paciente. $\mathrm{O}$ exame está dentro da sala, com a paciente. Leia o resultado e informe à paciente".

- Materiais necessários: um PP feminino, envelope escrito "exame", laudo com o nome da paciente e descrição de "HIV positivo".

\section{Progressões de cena e possíveis desfechos}

- Início da cena: a PP permanece calada, com braços e pernas cruzados e evitando contato visual. Esquivase de contato físico e recusará um possível aperto de mão do médico. Está ansiosa, interromperá conversas cotidianas e pedirá o resultado do exame.

- Ao receber o diagnóstico: abaixa a cabeça e permanece calada, paralisada, não chora. O ideal é que o médico respeite os instantes de silêncio ou a acolha com poucas palavras, pois tentativas de amenizar a situação com clichês como "Você poderá ter uma vida completamente normal" são respondidas pela PP com agressividade e ironia ("Normal? Você está dizendo que vai me curar?"). Se o médico for agressivo ou combativo, a agressividade da PP será crescente e impedirá a progressão da cena para o objetivo secundário. Se a PP for acolhida, ela passará a questionar o médico sobre a possibilidade de transmitir o vírus para outras pessoas, como o namorado, demonstrando bastante ansiedade na hipótese de colocá-lo em risco. Nenhuma resposta a tranquilizará, e ela repetirá: "Ele não tem culpa, não merece ficar doente. Eles... eles que fizeram isso comigo". Ao fim da consulta, se o médico for acolhedor, perceber as pistas e questioná-la sobre como poderá ajudá-la, a PP contará que possivelmente se infectou em um estupro. Se a abordagem do estudante participante for pouco acolhedora, ela não contará a violência ocorrida e deixará de ofertar pistas.

\section{Objetivo primário da cena}

Comunicação verbal do diagnóstico de HIV à PP.

\section{Objetivo secundário da cena}

Acolher a PP abrindo espaço de confiança na comunicação para que ela revele que sofreu violência sexual e obtenha acolhimento do participante.

\section{Elementos facilitadores}

A PP Mariana permitirá que o estudante participante fale o quanto quiser, mesmo que em demasia, de forma que a agressividade não impeça a fluidez da consulta.

\section{Resultados}

Tempo de construção de dez horas, 60 estudantes submetidos a cenas. Percepção de muita realidade em $70 \%$, alguma sensação de realidade em $27 \%$ e $3 \%$ permaneceram neutros.

\section{Caroline e Marcelo \\ Perfil}

Trata-se de um casal. Caroline é introvertida e gentil, e Marcelo é extrovertido e tende à agressividade. Enquanto Caroline é calada, o cônjuge é comunicativo em demasia e tenta "roubar" a cena.

- Postura na cena: ambos são sorridentes e simpáticos e indicam abertura para o diálogo. Estão sentados e de mãos dados. Alguma apreensão para conhecerem o diagnóstico. 


\section{Historicidade}

Ambos têm 35 anos e são casados há oito. Estão tentando engravidar há mais de dois anos. Há muito Caroline sonha em ser mãe e construiu sua vida em torno disso. Em consulta anterior, foram solicitados exames básicos para investigação de infertilidade conjugal, inclusive exame de imagem, uma ecografia pélvica transvaginal, para visualização de útero e ovário. O casal retorna neste momento para saber os resultados.

- Necessidade de adaptação de discurso: ambos conhecem termos veiculados nos meios de comunicação e aprendidos no ensino médio, e não compreenderão termos médicos específicos. Não compreenderão eufemismos ou informações vagas, e, se utilizados pelo médico, desviarão a atenção do diagnóstico e se mostrarão confusos, pedindo explicações como "O que isso quer dizer?".

\section{Instrução ofertada aos participantes das oficinas}

“Caroline, 35 anos, procurou a atenção primária à saúde há um mês porque deseja descobrir o motivo de não engravidar. Foram solicitados os primeiros exames. Hoje ela retornou com o esposo Marcelo para conhecer os resultados."

- Materiais necessários: dois PP (masculino e feminino), envelope com o nome da PP, laudo contendo o resultado"câncer no útero, tratamento recomendado é uma grande cirurgia que removerá o útero e a paciente não poderá engravidar". Irreversível.

\section{Progressões de cena e possíveis desfechos}

- Início da cena: o casal está animado, demonstra simpatia pelo médico e transborda felicidade e sem expectativa de receber uma má notícia. Marcelo sempre falará mais que a esposa, que muitas vezes apenas concordará e sorrirá.

- Ao receberem a notícia: Marcelo reage com energia e dúvida, questionará o diagnóstico e demonstrará medo. Se compreenderem que Caroline não poderá engravidar e ter os próprios filhos, ocorrerá nítida frustração ("Você está me dizendo que eu não vou ter filhos com a Caroline e que vou ficar sozinho no mundo?"). Caroline fica mais calada, perplexa, exceto em suas tentativas de acalmar o marido ("Calma, amor, deixa o médico falar"). Se o médico focar Caroline, Marcelo aos poucos permitirá que a cena flua melhor. Se o médico sugerir adoção ou uma vida sem filhos, Marcelo reagirá com mais agressividade, e haverá uma certa confusão na cena ("Isso não é uma possibilidade para nós"). Se o médico entrar em conflito com Marcelo, a comunicação não se desenvolverá. Caroline se manifestará apenas se questionada diretamente sobre o seu sofrimento. Ela perguntará da possibilidade de gestação, mas precisará de uma resposta mais clara para compreender a gravidade; logo, eufemismos e respostas evasivas podem confundir a paciente ("Tumor, que é um tumor? ou "Por que não posso tratar isso e engravidar depois?").

\section{Objetivo primário da cena}

Comunicar o diagnóstico de câncer de útero ao casal de PP, a indicação de cirurgia e a impossibilidade de gestar os próprios filhos.

\section{Objetivo secundário da cena}

Colocar Caroline como protagonista da consulta, permitir que ela se expresse, sem deixar de acolher ou entrar em conflito com o esposo Marcelo.

\section{Elementos facilitadores}

A própria Caroline acalma o marido a partir do quarto minuto para que o estudante participante tenha a oportunidade de cumprir o objetivo primário e comunicar o diagnóstico, mesmo que não consiga lidar com Marcelo. Essa foi a única simulação de permitiu duração estendida de até sete minutos devido à presença de dois PP em cena.

\section{Resultados}

Tempo de construção de oito horas, 53 estudantes submetidos a cenas. Percepção de muita realidade em $75 \%$ e alguma sensação de realidade em $25 \%$.

Thaís

Perfil

Extrovertida e comunicativa.

- Postura na cena: está sentada, sorridente, simpática e aberta para o diálogo. Cumprimenta o médico logo que ele entra no consultório.

\section{Historicidade}

A PP Thaís é uma mulher, 23 anos, casada e religiosa que tenta engravidar há dois anos de esposo, seu único parceiro. Está convicta da infertilidade do esposo. Nunca menstruou, e, desde adolescente, a mãe lhe ofertava um chá para "não ficar naqueles dias". Em uma outra consulta, foi solicitadas ecografia pélvica ("Aquele exame com gel aqui na barriga"), e hoje comparece para conhecer o resultado. 
- Necessidade de adaptação de discurso: a PP possui noções básicas de biologia ensinadas no ensino médio, mas não compreenderá termos técnicos ou eufemismos do médico.

\section{Instrução ofertada aos participantes das oficinas}

"Thaís, 23 anos, casada, religiosa e ensino médio completo. $\mathrm{Na}$ consulta anterior, foram solicitados exames, pois diz que deseja engravidar há dois anos do esposo. Nessa consulta, ela traz os resultados dos exames."

- Materiais necessários: uma PP feminina, envelope dentro do consultório com o nome da paciente e laudo de ecografia pélvica com a descrição "Ausência de útero e ovários. Presença de testículos bilaterais". Diagnóstico de insensibilidade androgênica. Irreversível.

\section{Progressões de cena e possíveis desfechos}

- Início da cena: a PP é simpática e conversa animadamente. Comenta que fez exames "só para checar" e que tem certeza de que está tudo certo com ela.

- Aoreceberodiagnóstico:entraráem choque, se retrairá e começará a rezar com as mãos em prece na mesa do médico. Olha para o médico e mostra-se confusa. De acordo com os valores da PP, a impossibilidade de ter filhos significa não cumprir o seu papel de mulher ("Doutor, eu não serei a mulher que devo ser dentro da minha fé se eu não engravidar"). Se o médico acolher o sofrimento, ela aceitará melhor a condição e passará a expor as preocupações. Sem uma abordagem adequada ou caso suas crenças sejam desrespeitadas, ela se tornará ríspida com o médico ("Doutor, você não entende a minha fé"). A PP tem dificuldade de compreender se é mulher ou homem e fará perguntas como "Deus fez o homem e a mulher... E eu sou o quê?". Ela também não compreenderá que não poderá ter filhos, exceto se comunicada claramente. Se o médico se mostrar insensível com seus valores, ela o ignorará o profissional e voltará rezar.

\section{Objetivo primário da cena}

Comunicar verbalmente que a paciente tem diagnóstico de insensibilidade androgênica ou que não tem órgãos reprodutores femininos e tem os masculinos pouco desenvolvidos, e, por conta disso, não poderá engravidar ou gestar.

\section{Objetivo secundário da cena}

Acolher e incluir a religiosidade da PP na consulta.

\section{Elementos facilitadores}

A paciente tem conhecimentos básicos de anatomia dos sistemas reprodutores feminino e masculino, compreenderá o que é ovário e testículo, para que a explicação da condição complexa não levasse tempo demasiado da cena.

\section{Resultados}

Tempo de construção de sete horas, 31 estudantes submetidos a cenas. Percepção de muita realidade em $32 \%$, alguma sensação de realidade em $58 \%$ e $10 \%$ permaneceram neutros ou não tiveram sensação de realidade.

\section{Roger ou Rosana}

Perfil

Agressivo(a) e autoritário(a). Esse PP foi desenvolvido de maneira que pudesse ser interpretado por estudantes atores homens ou mulheres.

- Postura na cena: aberto(a) para conflito e discussão. Estará em pé no início da cena, não quer cumprimentar ou se sentar. Apontará o relógio e reclamará do atraso do médico na primeira troca de palavras.

\section{Historicidade}

Homem/mulher, 38 anos, divorciado(a). Grosseiro(a), arrogante. É administrador(a) de uma grande empresa. A visão noturna e periférica piorou há seis meses. Ruby, filha com 8 anos, é importante e passa a maior parte do tempo com o ex-cônjuge. Dedica-se ao trabalho para ofertar compensação financeira à menina. A perda de visão dificultará tanto a vida profissional como a relação com a filha.

- Necessidade de adaptação do discurso: compreenderá o que o médico disser, mas reagirá com agressividade aos eufemismos ou termos técnicos.

\section{Instrução ofertada aos participantes das oficinas}

"Roger (ou Rosana), 38 anos, divorciado(a), procedente da capital. Realizou diversos exames no centro médico e trouxe hoje. Você está dez minutos atrasado para chamá-lo(a)".

- Materiais necessários: um PP (feminino ou masculino), um envelope com nome do/da paciente e laudo com a descrição "Doença degenerativa que causa perda progressiva de visão, sem tratamento. Irreversível". 


\section{Progressões de cena e possíveis desfechos}

- Início da cena: o(a) PP não cumprimentará o médico, não sentará e comentará irritado(a): "Se meus funcionários chegassem com esse atraso seriam demitidos". A expectativa do(a) PP é receber uma prescrição de óculos que resolverá o problema. Ele(a) apressará o médico para dar o diagnóstico, comentando que não quer perder mais tempo.

- Ao receber o diagnóstico: o(a) PP fica em negação e pergunta sobre tratamento em outros locais, como hospitais famosos, já que possui dinheiro. Se o médico for assertivo e educado, permitir pequenos momentos de silêncio após comunicar o diagnóstico e acolher o sofrimento do(a) PP em relação à filha, a agressividade será amenizada e a cena fluirá melhor. $\mathrm{Na}$ ausência de clareza e de assertividade ou se houver uma abordagem ríspida do médico, confrontando o(a) paciente, este/esta se tornará mais agressivo(a), com socos na mesa e voz alta. Naturalmente comentará que o emprego dele/ dela depende da visão, que pessoas dependem dele/dela (com referência à filha). O(a) PP ficará mais agressivo(a) ao receber sugestões de terapias que não sejam a cura. Questionado(a) sobre a filha, relata que a ama muito e fica abalado(a) com a possibilidade de não a ver crescer.

\section{Objetivo primário da cena}

Comunicar verbalmente o diagnóstico de retinose pigmentar, de perda de visão progressiva e que não há tratamento curativo.

\section{Objetivo secundário da cena}

Conseguir se comunicar com Roger (ou Rosana), acalmálo(a) e acolher o sofrimento em geral com relação à filha.

\section{Elementos facilitadores}

O(a) PP é agressivo(a), dificulta a cena e poderá causar constrangimento, mas a não humilhação do médico. Os comentários serão genéricos e não de caráter pessoal como "Estamos falando que a medicina do século XXI não desenvolveu a cura ainda?" e "Aposto que naquele hospital famoso conseguirão me curar".

\section{Resultados}

Tempo de construção de sete horas, 22 estudantes submetidos a cenas. Percepção de muita realidade em $82 \%$ e alguma sensação de realidade em $18 \%$.

\section{DISCUSSÃO}

A relação médico-paciente é um dos pilares da prática médica ética e humanizada ${ }^{14,15}$. Além de conhecimento científico e de habilidades técnicas, é importante que o curso de Medicina inclua no currículo o desenvolvimento de habilidades de comunicação, relacionamento interpessoal e empatia ${ }^{1,7,8,14-17}$. A comunicação de más notícias é um momento crítico da prática médica, em que a relação com o profissional poderá acolher o paciente e proporcionar acesso ao tratamento ou o inverso, o que poderá piorar a condição de saúde e a confiança nos serviços de saúde ${ }^{1-3}$. Este estudo demonstrou que os estudantes de Medicina foram capazes de compreender o cenário das relações médico-paciente e desenvolver PP para treinamento de habilidades de comunicação, propiciando treinamento para outros discentes do mesmo curso. Por meio de práticas teatrais e de improvisação, os estudantes atores puderam desenvolver a habilidade de comunicação, literalmente vivenciar o papel do paciente e ter a percepção do cenário e a autopercepção a partir da construção de PP.

No âmbito de educação médica, vários estudos indicaram a utilização do cenário simulado para aprendizado de técnicas de comunicação com benefícios ${ }^{6,9-13-15,18}$. No entanto, poucos artigos abordaram o método de construção de PP, o que dificulta a reprodutibilidade da metodologia no cotidiano de ensino acadêmico. Cada vez que um professor pretende usar cenários simulados e PP, há necessidade de desenvolver personagens, o que poderá deixar a prática frágil ou pouco real se a historicidade for superficial. Ainda, como no caso deste curso, nem sempre há recursos para a contratação de atores. Mesmo que haja recursos, os atores podem não ter expertise na área médica.

Nesse sentido, a descrição de PP apresentada aqui, com historicidade, análise das dificuldades, desfechos e descrição dos materiais, é um diferencial do presente estudo, que pode ser reproduzido em outras estratégias de ensino nos cursos de Medicina brasileiros. Não foram localizados outros estudos que abordassem a construção de PP e a qualidade das cenas para ensino da comunicação de más notícias.

Estudos sobre role playing como ferramenta educativa em geral empregaram atores profissionais ${ }^{7,13}$ por conta da falta de habilidades teatrais dos estudantes ${ }^{13}$. Outros estudos, no entanto, mostraram que o aprendizado dos estudantes pode ser potencializado quando eles se revezam nos papéis de médico, paciente, familiar e observador das cenas. Nesse sentido, a inversão de papéis estimulou o aprendizado, praticou o ato de se colocar no lugar do outro e estimulou o exercício da empatia ${ }^{6,10,18,19}$, que é uma habilidade essencial para a relação médico-paciente favorável e positiva ${ }^{14-17}$. A perda da empatia foi observada ao longo dos cursos de saúde 
em geral e, provavelmente, é um reflexo do enfrentamento das adversidades referentes ao ensino e às práticas em saúde vivenciadas pelos discentes ${ }^{18,19,20-22}$.

Outro ponto relevante refere-se ao fato de o processo de elaboração e interpretação dos PP propiciar a manifestação artística dos estudantes ${ }^{6}$, criando uma oportunidade para que possam expressar de forma cênica a criatividade e também angústias, ansiedades e medos. A manifestação afetiva dos discentes pode ter contribuído para o desenvolvimento de personagens com riqueza ímpar.

Vale ressaltar ainda o engajamento dos estudantes em todas as etapas do processo. Além de elaborarem e dramatizarem as cenas, eles se apropriaram gradativa e integralmente da metodologia. Existiu coesão no grupo, e, dos dez que se envolveram inicialmente, não houve desistências. Apesar de não fazer parte deste estudo, foi interessante observar que, ao longo do processo, uma amizade sólida se formou entre estudantes que não se conheciam previamente. As oficinas foram organizadas essencialmente pelos estudantes atores. $\mathrm{O}$ profissionalismo desenvolve-se quando se permite o exercício prático e supervisionado, com a valoração da experiência e reflexão das próprias condutas ${ }^{23-24}$.

Os aspectos abordados na construção de cada PP foram discutidos de forma agrupada: 1. perfil e historicidade, 2. progressão da cena e possíveis desfechos/gatilhos e reações diante da comunicação, e 3. objetivos primário e secundário, limitação e fatores de dificuldade de cena.

\section{Perfil e historicidade}

Os perfis definidos como introvertido, extrovertido, agressivo ou passivo serviram para estabelecer o tipo de desafio imposto na comunicação baseado em questões individuais. Por exemplo, médicos tendem a reagir de forma autoritária a personagens agressivos ${ }^{7}$, o que no caso de Roger e Marcelo poderia levar a um conflito intransponível nas encenações. Já a PP Caroline trouxe ao participante a dificuldade de estabelecer vínculo com uma paciente mais passiva, junto de esposo que dominava a comunicação, enquanto a introversão de Mariana gerava o desafio de ser acolhedor sem ser invasivo.

A historicidade do PP é um dos aspectos mais importantes, já que serve de base para as motivações do personagem e justifica o comportamento perante a comunicação da má notícia. A historicidade recrudesce a interpretação e traz profundidade e veracidade à cena ${ }^{3,7,12}$. Além disso, é uma forma de exercitar a empatia, já que os estudantes são provocados a compreender que cada paciente tem uma história e que muitas vezes o sofrimento é expresso por posturas que podem ser desagradáveis ao médico ${ }^{18,20-22}$. A adaptação do discurso explicou a familiaridade do personagem com termos e expressões médicos e interferiu diretamente no entendimento da condição de saúde. Uma ideia que não era compreendida poderia ser questionada. O profissional médico precisará estar apto a acessar diferentes níveis culturais e educacionais para se relacionar com o paciente de maneira beneficente, e não o contrário, com respeito ao nível de entendimento, cultura e valores do paciente $\mathrm{e}^{16,21}$.

\section{Progressão da cena e possíveis desfechos/gatilhos e reações diante da comunicação}

Foram construídos possíveis fluxos para as cenas. Definiuse previamente, de acordo com o temperamento de cada PP, que algumas abordagens do médico tornariam o PP mais aberto e amigável, enquanto outras o deixariam com mais raiva.

Gatilhos são conteúdos específicos que despertam reações distintas em cada personagem. Normalmente, consistem em chavões ou clichês, exposição de preconceitos ou mesmo manifestação de falta de empatia.

Por exemplo, se Caroline recebesse a sugestão de adoção, o casal reagiria de maneira negativa, pois se tratava da necessidade de acolher os valores primários da maternidade. Se o estudante não reconhecesse esse valor, a relação médico-paciente seria prejudicada. Da mesma forma, Mariana se tornaria mais agressiva se recebesse a sugestão de que poderia ter uma vida normal, pois se tratava da necessidade de acolher valores da paciente. Sabe-se que outras oportunidades poderão apontar para as PP, mas tais enfrentamentos dependem de tempo, elaboração pessoal e valores individuais, e não deveriam ser sugeridos pelo médico no momento da comunicação de más notícias ${ }^{4}$.

\section{Objetivos primário e secundário, limitação e fatores de dificuldade de cena}

O role playing é uma situação geradora de muita ansiedade para os estudantes por causa da característica de exposição, e, por isso, a ansiedade excessiva pode ser prejudicial ao aprendizado $6,9,13$.

Assim, percebeu-se, durante os ensaios, a necessidade de limitação da agressividade de alguns PP, visando minimizar o desconforto causado até um nível aceitável para a experiência educacional. Para isso, foram desenvolvidas regras, tais como: o personagem jamais representaria uma ameaça física, não ofenderia o médico pessoalmente e não questionaria a qualidade da sua formação acadêmica. Além disso, esclareceuse a todos participantes e PP que os estudantes seriam observados apenas no quesito da comunicação, não levando em conta seus conhecimentos técnicos em medicina. Isso foi necessário tanto para incluir estudantes de todos os períodos quanto para reduzir o estresse causado pela pressão de estar 
sendo avaliado. Em outros estudos, os fatores facilitadores também foram estabelecidos para mediar cenas muito complexas. As simulações são desenhadas para que possam ser desafiadoras, mas não impossíveis, de modo a maximizar assim o aprendizado ${ }^{9,13}$.

O objetivo primário de todas as cenas era a comunicação clara e direta da má notícia. O objetivo secundário era um elemento que só seria alcançado pelo estudante participante se o PP se sentisse verdadeiramente acolhido em seu sofrimento. Para Mariana, por exemplo, o objetivo secundário era descobrir que ela sofrera violência sexual, algo que a personagem só revelaria se o médico respeitasse sua introversão, ouvisse suas angústias e demonstrasse empatia. Era uma forma de mostrar aos estudantes que as implicações possíveis de um diagnóstico desfavorável na vida de um paciente muitas vezes estão além do óbvio ou do falado.

A utilização no role playing de estudantes que não eram atores profissionais pode ter dificultado um pouco o processo, ainda que tenha sido o diferencial positivo deste estudo. Entretanto, na maior parte das cenas, os participantes apontaram sensação de realidade boa ou excelente. Assim, não consideramos que o emprego de estudantes tenha comprometido a experiência. Acrescenta-se ainda que a não utilização de atores tornou a experiência economicamente viável de ser reproduzida em outros cursos de Medicina que não tenham recursos para contratar atores.

Os diagnósticos que serviram de base para as cenas foram utilizados como ferramentas narrativas. A pouca acurácia na representação de algumas doenças pode ter sido uma limitação deste estudo, o que poderá ser aprimorado em outros trabalhos. No entanto, como o aprimoramento das habilidades diagnósticas não foi o foco da experiência relatada, não consideramos essa uma limitação importante a ser aprimorada.

A sensação de realidade descrita pelos estudantes foi considerada como um marcador de qualidade das cenas desenvolvidas. $O$ estudante participante que teve sensação de realidade provavelmente foi mais sensibilizado pelo aprendizado na oficina. Assim, a cena de menor realidade (Thaís) deverá ser aprimorada no futuro.

\section{CONSIDERAÇÕES FINAIS}

O objetivo deste estudo foi construir cenas com PP para a realização de simulação no ensino médico. Embora o role playing não faça parte do cotidiano da maior parte dos cursos de Medicina, a literatura aponta para a possibilidade de benefícios na educação médica.

Como este estudo demonstrou, foi possível construir quatro cenas com PP para a simulação em cenários de comunicação de más notícias do tipo role playing com participação de estudantes de Medicina. As cenas, em sua maioria, mostraram sensação de realidade quando interpretadas em oficinas, permitindo o ensino médico vivencial da comunicação de más notícias.

Assim, a partir dessa construção, as cenas poderão ser reutilizadas em outras experiências de ensino e auxiliar na formação dos futuros médicos para os desafios da prática assistencial e da comunicação de más notícias.

\section{AGRADECIMENTOS}

As autoras agradecem às professoras de teatro Raquel Júlio Mastey e Nádia Lomardo, cujo auxílio foi fundamental para o desenvolvimento deste estudo, aos estudantes que participaram das encenações como pacientes e médicos simulados, e à instituição onde se realizou o estudo.

\section{CONTRIBUIÇÃO DAS AUTORAS}

A coleta de dados foi realizada por todas as autoras. Ana Paula Rosa Isquierdo transcreveu os resultados para o Excel. A interpretação dos resultados foi realizada em grupo, com todas as autoras, sob orientação de Ursula Bueno do Prado Guirro. A busca por artigos de revisão foi realizada por todas as autoras. Todas as autoras participaram da preparação do manuscrito, incluindo introdução, revisão de literatura, metodologia, resultados e discussão dos resultados. A preparação do manuscrito conforme as normas solicitadas pela revista coube a Fernanda Cristine Quint.

\section{CONFLITO DE INTERESSES}

Declaramos não haver conflito de interesses.

\section{FINANCIAMENTO}

Declaramos não haver financiamento.

\section{REFERÊNCIAS}

1. Buckman R. Breaking bad news: why is it still so difficult? Br Med J 1984;288(26):1597-9.

2. Buckman R, Kason Y. How to break bad news: a guide for health care professionals. Baltimore: The Johns Hopkins University Press; 1992.

3. Buckman R. Practical plans for difficult conversations in medicine: strategies that work. Baltimore: The Johns Hopkins University Press; 2010.

4. Walter FB, Buckman R, Lenzi R, Glober G, Beale EA, Kudelka AP. SPIKES - A six-step protocol for delivering bad news: application to the patient with cancer. Oncologist. 2000;5(4):302-11.

5. Perosa GB, Ranzani PM. Capacitação do médico para comunicar más notícias à criança. Rev Bras Educ Med. 2008;32(4):468-73.

6. Jucá NBH, Gomes AMDA, Mendes LS, Gomes DM, Martins BVL, Silva CMGC, et al. A comunicação do diagnóstico "sombrio" na relação médicopaciente entre estudantes de Medicina: uma experiência de dramatização na educação médica. Rev Bras Educ Med. 2010;34(1):57-64.

7. Sutton RB. Supporting the bereaved relative: reflections on the actor's experience. Med Educ. 1998;32(6):622-9. 
8. Pereira AT, Gallian DMC, Reginato V, de Benedetto MAC. Percepção de alunos de medicina com a dramatização: uma experiência pedagógica. Rev Bras Educ Med. 2015;40(3):497-505.

9. Joyner B, Young L. Teaching medical students using role play: twelve tips for successful role plays. Med Teach. 2006;28(3):225-9.

10. Rabelo L, Garcia VL. Role-play para o desenvolvimento de habilidades de comunicação e relacionais. Rev Bras Educ Med. 2015;39(4):586-96.

11. Nestel D, Tierney T. Role-play for medical students learning about communication: guidelines for maximizing benefits. BMC Med Educ. 2007;7(3):1-9.

12. Baile WF, Blatner A. Teaching communication skills: using action methods to enhance role-play in problem-based learning. Simul Healthc. 2014;9(4):220-7.

13. Jackson VA, Back AL. Teaching communication skills using role-play: an experience-based guide for educators. J Palliat Med. 2011;14(6):775-80.

14. Isquierdo APR, Bilek ES, Guirro UBP. Comunicação de más notícias: do ensino médico à prática. Rev Bioét (Impr.). 2021;29(2):344-53.

15. Isquierdo APR, Miranda GFF, Quint FC, Pereira AL, Guirro UBP. Comunicação de más notícias com pacientes padronizados: uma estratégia de ensino para estudantes de Medicina. Rev Bras Educ Med. 2021;45(2):e091.

16. Costa FDD, Azevedo RCSD. Empatia, relação médico-paciente e formação em medicina: um olhar qualitativo. Rev Bras Educ Med. 2010;34(2):261-9.
17. Caprara A, Franco ALES. A relação paciente-médico: para uma humanização da prática médica. Cad Saude Publica. 1999;15(3):647-54.

18. Stanley C, Lindsay S, Parker K, Kawamura A, Zubairi MS. Value of collaboration with standardized patients and patient facilitators in enhancing reflection during the process of building a simulation. J Contin Educ Health Prof. 2018:1-6.

19. Darze OISP, Barroso Júnior U. Uma proposta educativa para abordar objeção de consciência em saúde reprodutiva durante o ensino médico. Rev Bras Educ Med. 2018;42(4):155-64.

20. Nascimento HCF, Ferreira Júnior WA, Silva AMTC, de Carvalho IGM, Bastos GCFC, de Almeida RJ. Análise dos níveis de empatia de estudantes de medicina. Rev Bras Educ Med. 2018;42(1):150-8.

21. Hurst SA, Baroffio A, Ummel M, Burn CL. Helping medical students to acquire a deeper understanding of truth-telling. Med Educ Online. 2015;20(28133):1-11.

22. Choe EK, Duarte ME, Suh H, Pratt W, Kientz JA. Communicating bad news: insights for the design of consumer health technologies. J Med Internet Res. 2019;6(2):1-19.

23. Ramos-Cerqueira ATDA, Lima MCP. A formação da identidade do médico: implicações para o ensino de graduação em medicina. Interface (Botucatu). 2002;6(11):107-16.

24. Pellegrino ED. Thomasma DC. Para o bem do paciente: a restauração da beneficência nos cuidados da saúde. São Paulo: Edições Loyola; 2018. 